\title{
Effect of Different Types of Polymers as Well as Different Preparation Techniques on the In-Vitro Release of Dyphylline Controlled Release Matrix Tablets
}

Heba A. Yassin ( $\nabla$ Heba_yassin@eru.edu.eg )

Tanta University

Mohamed A. Sharaf

Zagazig University

Hanna A. El-Ghamry

Zagazig University

Abdelaziz E. Abdelaziz

Kafrelsheikh University

\section{Research Article}

Keywords: Dyphylline, Wet granulation, Direct compression, Hot melts method, Controlled release system, Matrix tablets, Kinetic analysis.

Posted Date: February 19th, 2021

DOl: https://doi.org/10.21203/rs.3.rs-211212/v1

License: (c) (i) This work is licensed under a Creative Commons Attribution 4.0 International License.

Read Full License 


\title{
Effect of different types of polymers as well as different preparation techniques on the in-vitro release of dyphylline controlled release matrix tablets
}

\author{
Heba A. Yassin ${ }^{1}$, Mohamed A. Sharaf ${ }^{2}$, Hanna A. El-Ghamry², Abdelaziz E. Abdelaziz ${ }^{3}$ \\ ${ }^{1}$ Pharmaceutical Technology Department, Faculty of Pharmacy, Al-Salam University, Tanta, Egypt \\ ${ }^{2}$ Pharmaceutical Technology Department, Faculty of Pharmacy, Zagazig University, Zagazig, Egypt \\ ${ }^{3}$ Pharmaceutical Technology Department, Faculty of Pharmacy, Kafrelsheikh University, Kafrelsheikh, Egypt \\ Corresponding Author: Heba A. Yassin, E-Mail: Heba_yassin@eru.edu.eg
}

\section{Abstract:}

Dyphylline, xanthine derivatives, is used to manage asthma, cardiac dyspnea, chronic bronchitis, and emphysema. This work aimed to develop controlled release matrix tablets of Dyphylline using different types of polymers, and different preparation techniques such as direct compression, wet granulation, and hot melt methods. The prepared matrix tablets were evaluated by Infrared spectral analysis, differential thermal analysis, evaluation which included hardness, friability, content uniformity, and the in-vitro drug release. Kinetic analysis of the release profiles was investigated using different kinetic orders. All Dyphylline formulae obey Higuchi's diffusion model. The diffusion is the mechanism of Dyphylline release from its controlled matrix tablets. IR and DSC revealed no incompatibility between Dyphylline and the polymers used in the prepared formulae. The obtained results revealed that the wet granulation technique using water as the granulating liquid is the best method for the formulation of Dyphylline hydrophilic matrix tablets compared with the other techniques. The high content of polymers led to the high value of $\mathrm{T}_{1 / 2}$, and a decrease in Dyphylline's extent due to the improvement of the retention of drug release. A synergistic effect was obtained using PVP-K-25 in the hydrophilic matrix tablets, which led to the retention of the drug release.

Keywords: Dyphylline, Wet granulation, Direct compression, Hot melts method, Controlled release system, Matrix tablets, Kinetic analysis.

\section{1- Introduction:}

Controlled-release dosage forms are formulations from which one or more drugs are released continuously in a specific pattern for a fixed duration for local or systemic effects on the specified target organ. Controlled release formulations provide better preserving with the highest and adequate drug levels for an extended period with less frequency and complications $(\mathbf{1}, \mathbf{2})$.

The aim of formulating controlled-release systems is reducing the dose frequency, increasing the drug effectiveness by reducing the required dose as well as providing a uniform drug delivery system $(\mathbf{3}, \mathbf{4})$. 
Controlled-release of the drug means the extending of the duration of the drug delivery, as in the prolonged-release system, as well as implying predictability and reproducibility of drug release kinetics (5). There are many techniques by which tablets are suitable drug delivery system can be obtained.

\subsection{Wet granulation technique:}

Granules are formed by adding the liquid of granulation onto powder, which is under the, Effect of an impeller, screws, and air. The agitation obtained from the wetting process leads to the aggregation of the primary powder particles and producing the wet granules. The solvents used as liquids of granulation must be volatile, non-toxic, and can be removed by drying. The liquid of granulation includes water, ethanol, and isopropanol either alone or in combination. The liquid of granulation may be aqueous solvents or non-aqueous solvents. Aqueous solutions are safer than non-aqueous solvents (6).

\subsection{Direct compression technique:}

Direct compression is the technique by which tablets are compressed directly using mixtures of the drug and excipients (7). The simple formula consists of an active constituent, a lubricant, and a diluent (8). Direct compression technique has many advantages over the other manufacturing techniques used for tablet preparations and provides high efficiency (9). Tablets prepared by this technique give minimal microbial levels than others prepared by the wet granulation technique. The compaction process exerts a fatal effect on the survival of microorganisms $(\mathbf{1 0}, \mathbf{1 1})$. The main limitation of this technique is using more than $30 \%$ of the drug in the formulation, mainly for drugs with low segregation and flowability $(\mathbf{1 2}, \mathbf{1 3})$.

\subsection{Hot-melt technique:}

Hot-melt granulation is a technique by which the powders are agglomerated using meltable binders, which may be hydrophilic or hydrophobic, preferred in the preparation of the controlled-release formulations $(\mathbf{1 4}, \mathbf{1 5})$.

Dyphylline is (2, 3-dihydroxy propyl)-1, 3-dimethyl-2, 3, 6, 7-tetrahydro-1H-purine-2, 6-dione (Figure 1) (16). It is used in the management of asthma, cardiac dyspnea, chronic bronchitis as well as emphysema. Dyphylline has similar pharmacological actions as theophylline and other members of this class of drugs (17). Dyphylline exhibits peripheral vasodilation as well as smooth muscle relaxation. Dyphylline is a phosphodiesterase inhibitor that increases cyclic AMP, produces relaxation of bronchial smooth muscle, and antagonizes adenosine receptors (18).

\section{Figure 1}


Thus, the present work aimed to develop Dyphylline controlled release matrix tablets which release their contents over for 12 hours using different polymers and different preparation methods as well as studying the, Effect of different types of polymers and different preparation techniques on the invitro release of the drug from its controlled release matrix tablets. All tablet formulae prepared will be evaluated when freshly prepared, and promising tablet formulae that release their contents over 12 hours will be selected and subjected to scaling-up.

\section{2- Materials:}

Dyphylline, Merck AG, Germany, PVP K-25, ISP, Switzerland, Lactose monohydrate, DMV Campina B.V., Holland, Magnesium stearate, Union driva, England, HPMC E4M CR , viscosity of 2\% aqueous solution is 3000 - 5600 cps, Colorcon Ltd, England, Methocel K100M CR , viscosity of $2 \%$ aqueous solution is $80000-100000 \mathrm{cps}$, Colorcon Ltd, England, Hydroxy propyl cellulose (HPC)-MF, Hercules, USA, Hydroxy ethylcellulose (HEC), Hercules, USA, Compritol ATO 888 , Gatefossé, France, Precirol ATO 5, Gatefossé , France, Sodium alginate, FMC, USA, Alginic acid, FMC, USA, Xanthan gum, Courtesy of Alexandria Co. for Pharmaceuticals and Chemical industries, Isopropyl alcohol, BDH Chemicals, Poole, England, Microcrystalline cellulose (Avicel PH 102), FMC, USA, Sodium hydroxide, Potassium dihydrogen phosphate and tribasic sodium phosphate, El Nasr Pharmaceutical Chemical Co., Cairo (Egypt), Nanometer-size amorphous silicon dioxide, Cab-O-Sil (Spectrum Chemical Manufacturing Corporation, Gardena, CA, All materials were in analytical grade and were used.

\section{3- Methods:}

\subsection{Design of Dyphylline controlled release matrix tablets:}

Ten different hydrophilic, and hydrophobic polymers were used alone and in combination to prepare several tablet formulae applying three methods of preparation (direct compression, wet granulation, and hot melt). All formulae contained $100 \mathrm{mg}$ Dyphylline per tablet. Two hundred tablets were prepared for each formula using suitable filler to obtain the constant weight of the tablet at $850 \mathrm{mg}$. Talc (1\%) was used as a glidant, and magnesium stearate $(0.25 \%)$ was also used as a lubricant. The composition of the prepared formulae is illustrated in Table (1).

\subsubsection{Preparation of Dyphylline controlled-release tablets using direct compression technique:}

Twenty-seven tablet formulae were prepared by direct compression applying two variables, namely, polymer type (9 polymers) and polymer concentration (7, 14, and 21\%) using the single punch tablet machine (Type AR 400, Erweka Heusenstamm, Germany). Tables (1-3) exhibit the composition of the designed formulae. Avicel PH 102 was used as the filler, where it was mixed with Dyphylline using a mortar and a pestle for 5 minutes, then, mixed with the specified polymer by geometric dilution for extra 5 minutes. The obtained blends were mixed with magnesium 
stearate and talc and then compressed in a single $20 \mathrm{~mm}$ oblong punches. The force of compression at ten kpsi was kept constant.

\subsubsection{Formulation of Dyphylline controlled release matrix tablets using wet granulation technique:}

Preliminary studies were done to determine the optimum preparation conditions using $14 \%$ xanthan gum as a model polymer. To determine the optimum amount of the granulating agent, three different volumes of water were applied (250, 300, and $375 \mathrm{mg} / \mathrm{tablet})$, and the produced tablets were evaluated for their release profile. Granules with three different mean particle sizes (780, 950 and, $1350 \mathrm{um}$ ) were tested. The effect of the tablet surface area was studied using three punches (16 $\mathrm{mm}$ circular, $20 \mathrm{~mm}$ oblong plain, and $20 \mathrm{~mm}$ oblong bisected punches). Similarly, the compression force was varied 8,10 , and $12 \mathrm{kpsi}$, and the tablets were evaluated.

Forty-two Dyphylline tablet formulae were prepared using the wet granulation technique with seven different types of polymers, each at three concentrations, and applying water or isopropyl alcohol as the granulating agent. The used polymers were: Xanthan gum, Sodium alginate, Alginic acid, HPMC K100M CR, HPMC E4M CR, HPC and HEC, formulae, numbers $1_{\mathrm{ww}}-21_{\mathrm{ww}}$ and $1_{\text {wi- }} 21_{\mathrm{wi}}$ (Table 1). Lactose monohydrate was selected as the filler in all formulae. A mixture of the drug and the filler was mixed geometrically with the specific amount of the polymer and then kneaded using the selected granulating liquid. The obtained mass was passed through a $1 \mathrm{~cm}$ sieve and dried in a hot air oven at $60^{\circ} \mathrm{C}$ for 20 minutes in case of isopropyl alcohol and 60 minutes in case of water. The dried mass was then passed through a $1 \mathrm{~mm}$ sieve. Finally, the obtained blends were mixed with magnesium stearate $(0.25 \%)$ and talc $(1 \%)$ and then compressed in a single $20 \mathrm{~mm}$ oblong punch. The force of compression at ten kpsi was kept constant.

For further optimization of the tablets, a set of four tablet formulae was prepared to apply mixtures of polymers, (Table 2). Another set of five tablet formulae was prepared with the addition of $1 \%$ PVP K-25, (Table 3).

\subsubsection{Preparation of Dyphylline controlled-release tablets using a hot-melt technique}

Six formulae were prepared by the hot-melt method applying two preparation variables (polymer type and polymer concentration). Formulae number $22_{\mathrm{H}}-27_{\mathrm{H}}$, (Table 1 ). The drug was mixed with the waxy polymer (Compritol ATO 888 or Precirol ATO 5) using a mortar and a pestle for 5 minutes, poured in open Petri dishes, and placed in a hot air oven at $80^{\circ} \mathrm{C} \pm 2$ for 30 minutes with occasional mixing every 5 minutes, then cooled to room temperature. The obtained mass was passed through a $1 \mathrm{~mm}$ sieve and mixed with the diluent (Avicel PH 102) and lubricants in a mortar. The obtained blends were compressed in a single $20 \mathrm{~mm}$ oblong punches and dies. The force of compression at ten kpsi was kept constant. 


\section{Table 1}

\section{Table 2}

Table 3

\subsection{Infrared spectral analysis (FTIR):}

The spectrum of FTIR was applied to know if any types of interactions were found between the drug and the polymers used in the prepared formulae. The infrared spectra of the samples were by the use of a spectrophotometer (Espectrómetro Vertex 70, France). Samples were mixed with potassium bromide (spectroscopic grade) and then compressed into discs using a hydraulic press. Finally, the samples were scanned in the range of 4000 and $400 \mathrm{~cm}^{-1}(\mathbf{1 9})$.

\subsection{Differential Scanning Calorimetry (DSC):}

The physical state of the drug in the prepared formulae was analyzed by Differential Scanning Calorimeter Analyzer (DSC 204 F1 Nevio, Proteus ${ }^{\circledR}$ software extensions). The thermograms of the samples were determined at a temperature range of $10^{\circ} \mathrm{C}$ to $300^{\circ} \mathrm{C}$ and a scanning rate of $20^{\circ} \mathrm{C} / \mathrm{min}$ (20).

\subsection{Evaluation of the blends to be compressed:}

The flowability of the tablet blends prepared by direct compression was evaluated by using the fixed height cone method. The angle of repose was determined by the use of the following equation: Tan $\boldsymbol{\Theta}=2 \mathrm{~h} / \mathrm{d}$, Where $(\mathrm{h})$ and $(\mathrm{d})$ are the cone height and diameter, respectively (21).

\subsection{In-vitro; Evaluation of the prepared tablets:}

The following quality control tests were done on the prepared formulae:

\subsubsection{Hardness:}

Hardness demonstrates the ability of a tablet to withstand mechanical shocks while handling. This test is carried out using a TestCoat hardness tester (Digital Vickers Hardness Tester LHV - 50Z, Motorized Turret Function, 16.5 MSH, USA). The value is expressed in $\mathrm{kg} . \mathrm{cm}^{-2}$. Ten tablets were chosen randomly, and the Hardness of the formulated tablets was calculated (22).

\subsubsection{Friability:}

Grace Digital Friabilator, USA, was used for testing the strength of tablets. Friability is calculated in percentage (\%). Ten tablets were weighed and put into the apparatus (23). The Friabilator was operated at $20 \mathrm{rpm}$ for $5 \mathrm{~min}$ or run up to 100 revolutions. The tablets were weighed again. The percentage friability was then determined by: 


\section{$\%$ Friability $=\mathrm{W}_{0}-\mathrm{W} / \mathrm{W}_{0} \times 100 \quad$ Eq. (1)}

Where $\mathrm{W}_{\mathrm{o}}$ : the initial weight of tablets, $\mathrm{W}$ : the final weight of tablets

$\%$ friability of tablets less than $1 \%$ are in the accepted range.

\subsubsection{Content uniformity:}

The drug content uniformity was calculated by crushing ten tablets from each formula, and the content of each tablet was determined individually (24). The powder equivalent to one tablet was dissolved in $50 \mathrm{ml}$ water. The solution was then filtered through a $0.45 \mathrm{um}$ Millipore filter and adequately diluted with water. The absorbance was Spectrophotmetrically measured at the predetermined $\lambda_{\max }$ of $276 \mathrm{~nm}$ (Single Beam UV-VIS Spectrophotometer, (LT-291), Japan) drug content of each tablet was determined. The results were presented as the mean drug content \pm SD. The tablets meet the test if the average drug content lies within the range of $85-115 \%$ of the label claim and the standard deviation is less than $6 \%$.

\subsubsection{In-vitro drug release studies:}

The cumulative release of Dyphylline from its tablets was performed according to the general USP XXV rotating paddle method (Type II, Paddle type, Copley, England), at a paddle speed of 100 $\mathrm{rpm}$, in a gradient $\mathrm{pH}$ system of $750 \mathrm{ml}$ of $0.1 \mathrm{~N} \mathrm{HCl}$ for 1 hour (representing stomach) followed by phosphate buffer $\mathrm{pH}$ equal 6.8 for 3 hours (representing jejunum) and phosphate buffer $\mathrm{pH}$ equal 7.4 for 8 hours (representing ileum). The temperature should be adjusted to $37 \pm 0.5^{\circ} \mathrm{C}$. The paddle was placed at a distance of $3 \mathrm{~cm}$ from the bottom of the vessel. At appropriate time intervals of 1, 2, 4, 6, 8, and 12 hours, $10 \mathrm{ml}$ of the solution was withdrawn from the release medium, then filtered through a 0.45 Millipore filter and replaced with the same amount of the fresh release medium to keep the sink condition. The filtered samples were analyzed using a UV spectrophotometer by measuring the absorbance of Dyphylline at $\lambda_{\max } 276 \mathrm{~nm}$ using $0.1 \mathrm{~N} \mathrm{HCl}$, phosphate buffer $\mathrm{pH} 6.8$, and phosphate buffer pH 7.4 as blanks respectively. Each experiment was carried out three times.

The mean dissolution time (MDT) was calculated for all in-vitro dissolution profiles using the next equation:

$$
\mathbf{M D T}=\frac{\sum_{i-1}^{n} \mathbf{t}_{\text {mid }} x \Delta \mathbf{M}}{\sum_{i-1}^{n} \Delta \mathbf{M}}
$$

Where $i$ represents the number of the dissolution sample, $n$ represents the dissolution sample time number, $t_{\text {mid }}$ represents the midpoint time between $i$ and $i-1$, and $\Delta M$ represents the extra amount of drug dissolved between $i$ and $i-1$; the higher the MDT, the slower the dissolution rate of the drug. A hypothetical target release profile was designed and used as a reference to evaluate the prepared tablets. This target profile assumed that $100 \%$ of the drug content is released from the tablets after 12 hours following Higuchi release kinetics. The percent drug released at the intermediate time intervals was based on the USP official drug monograph. For selecting the most promising tablet 
formula, the similarity factor $f_{2}$ was determined according to the next equation:

$$
f_{2}=50 \log \left\{\left[1+\frac{1}{n} \sum_{n=1}^{n} W_{t}\left(R_{t}-T_{t}\right)^{2}\right]^{-0.5} \times 100\right\} \quad \text { Eq. (3) }
$$

Where $\mathrm{n}$ represents the sample point's number, $\mathrm{w}_{\mathrm{t}}$ represents the optional weight factor, $\mathrm{R}_{\mathrm{t}}$ represents the reference profile, the $f_{2}$ value should be between 50 and 100. An $f_{2}$ of 100 suggests that the test and reference profiles are the same.

\subsection{Kinetic models of the In-vitro release data:}

To investigate the possible kinetic model of drug release from tested formulations, the release data obtained were fitted into various kinetic models, namely, Korsmeyer-Peppas, zero-order, Higuchi model, and first-order.

\subsubsection{Zero-order kinetics: $\quad Q=$ ko.t $\quad$ Eq. (4)}

Where $\mathbf{k}_{\mathbf{0}}$ represents the rate constant of the zero-order expressed in units of concentration/time, in zero order, the concentration of the drug was plotted against the time. The rate constant of the zero-order $\mathrm{k}_{0}$ and the regression line $\left(\mathrm{R}^{2}\right)$ values were also determined from the graph. The zeroorder rate equation (4) exhibits that the release rate of the drug is concentration-independent (25).

\subsubsection{First-order kinetics:}

$$
\log Q=\log Q_{0}-k_{1} t / 2.303
$$

Where $\mathbf{Q}_{\mathbf{0}}$ represents the initial amount of drug and $\mathrm{k}$ is the rate constant of the first-order. In the first-order release kinetics, the $\log$ cumulative \% drug remaining $\left(\log \mathbf{Q}_{\mathbf{0}}\right.$-Log $\left.\mathbf{Q}\right)$ was plotted against the time. The rate constant of the first-order $\mathrm{k}_{1}$ and the regression line $\left(\mathrm{R}^{2}\right)$ values were also determined from the graph. The first-order equation (5) exhibits that the release rate of the drug is dependent on its concentration (25).

\subsubsection{Higuchi's kinetics:

$$
\mathbf{Q}=\mathbf{k} \cdot \mathbf{t}^{1 / 2}
$$

Higuchi 1963 (26) explained the mechanism of the release of drugs from the insoluble-matrix as a square root of a time-dependent process based on Fickian diffusion Equation (6). Higuchi model relates the relationship between the quantity of drug released $(\mathrm{Q})$ and the square root of time $\mathbf{t}^{\mathbf{1} / \mathbf{2}}$. The amount of drug released was plotted against the square root of time. The Higuchi release constant $\mathrm{k}$ and $\mathrm{R}^{2}$ values were also determined from the graph. The Higuchi constant shows the variables of the system design. Subsequently, the drug release rate is proportional to the reciprocal of the square root of time. Where $\mathbf{Q}$ represents the amount of drug released at the time (t), and $k$ represents the constant rate of the release $(\mathbf{2 7}, \mathbf{3 0})$.
3.6.4. Korsmeyer-Peppas equation:
$M_{t}=M_{0}+K_{p} \cdot t^{n}$
Eq. (7) 
Where $M_{t}$ represents the percent of drug released at time $t, M_{o}$, corresponds to the initial amount of drug released after an infinite time, $\mathrm{K}_{\mathrm{p}}$ represents constant incorporating structural and geometric characteristics of the release device, and $\mathrm{n}$ is the release exponent indicates of the mechanism of release. The $n$ values used to illustrate the drug release mechanism from the tablets were determined from the cumulative log percentage of drug released versus log time plots (28-30).

The correlation coefficient in each of the four cases was determined. The kinetic parameters: Rate constants $(\mathrm{K})$ and half-lives $\left(\mathrm{t}^{1 / 2}\right)$ were then computed according to the determined order.

\section{4- Statistical Analysis:}

One way ANOVA test was used for comparisons between the different prepared formulae. Data were presented as Mean $\pm \mathrm{SD}$. The $\mathrm{P}$ values $<0.05$ were considered as the significance level during this study.

\section{5- Results and discussion:}

\subsection{Infrared spectral analysis (FTIR):}

The FT-IR spectra of Dyphylline with HPMC, HPC, HEC, compritol, and precirol are illustrated in Figure (2-I). The FT-IR spectra of Dyphylline with xanthan gum and alginates are illustrated in Figure (2- II).

\section{Figure 2}

Figure 2 revealed that the valleys in the Dyphyline spectrum at 3460, 3320, 3110, 1705, and 1660 $\mathrm{cm}^{-1}$ were due to the stretching vibrations of intramolecular hydrogen-bonded $-\mathrm{OH},=\mathrm{CH}$, hydrogen-bonded $-\mathrm{NH}$, non-conjugated $\mathrm{C}=\mathrm{O}$, and amide groups, respectively. Dyphylline retained its central valleys in both the binary mixtures, suggesting its compatibility with all polymers used. FTIR studies showed no appearance of any new peaks or disappear off the original peaks, which confirmed that there is not any type of interactions or any incompatibility between Dyphylline and the chosen polymers.

\subsection{Differential Scanning Calorimetry (DSC):}

Figure 3 shows the DSC thermograms of Dyphylline with the chosen polymers comparing with the free drug.

\section{Figure 3}

Differential scanning calorimetric analysis was done to emphasize the absence of any interaction between the drug and polymer used and was done for the same samples tested by the FTIR technique. DSC thermograms exhibited that is no interaction between Dyphylline and the chosen polymers. Drug excipient interaction may lead to peak appearance or disappearance, change in peak 
shape, size, and position. Dyphylline showed melting at about $163{ }^{\circ} \mathrm{C}$. In all the thermograms of mixtures, the drug peak was retained. The peaks were somewhat broadened and shifted to lower temperatures. However, shifts were only less than $10^{\circ} \mathrm{C}$. Peak broadening and shift of the endothermic peak were probably due to the intermixed nature of the components, not interaction. These small shifts of the values should signify minor interactions of the components. However, this could only be due to physical interaction without changing the chemical nature of the components.

\subsection{Evaluation of compressed tablets:}

Table 4 represents the angle of repose of Dyphylline tablet blends intended for preparation by direct compression.

\section{Table 4}

Table 4 shows that the angle of repose values for the tested blends was close, and their range (36 $45^{\circ}$ ) demonstrated fair flow properties, and that may hang, and thus, a glidant, and a lubricant were used.

\subsubsection{Hardness and Friability:}

The mean hardness values of ten tablets of each formula are presented in Table 5. Different formulae of Dyphylline controlled release matrix tablets prepared by different polymers showed closely related hardness values ranging from $13-16 \mathrm{~kg}$, with a standard deviation of less than $2 \%$.

Friability measurement is the most common experimental procedure to determine if the tablet is prone to erode mechanically during handling and determine the attrition resistance of tablets. The friability of all formulae was determined and listed in Table 5. The Friability percentage of the prepared formulae was less than $1 \%$, which confirms that the compressed tablets are in the acceptable range (31).

\subsubsection{Content Uniformity:}

Table 5 shows the drug content average of 10 tablets from each formula. It is worthy to note that all formulae comply with the pharmacopeia limits, i.e., the drug content average of all formulae is in between the range of $85 \%-115 \%$ of the label claim, and the standard deviation was less than $4 \%$.

\section{Table 5}

\subsubsection{In-vitro drug release studies:}

The In-vitro release of the Dyphylline controlled-release tablets was studied in a pH-gradient dissolution medium. The dissolution profiles were exhibited in Figure 4. It is worthy to note that the percentage of drug dissolved was determined according to the percentage drug content determined for each formula. For assessment and comparison, the MDT and the similarity with the reference 
release profile were calculated. The Effect of type and content of controlled release matrix on the release of Dyphylline from the prepared formulae was assessed individually.

\section{Fig. 4}

From Figure (4), it is evident that the increase in xanthan gum, alginic acid, HEC, and HPC did not show any change in percent Dyphylline released. This was attributed to the hydrophilic nature of these polymers as they need water to hydrate and produce the gel layer responsible for drug retardation. Those four polymers, at their three concentrations, failed to control the drug release. They released $100 \%$ of their drug loadings in less than one h. it was recording short MDT values $(0.506$ h. $)$ and high dissimilarity with the target release profile $\left(f_{2}=16.67\right)$. The increase in the polymer concentration led to a decreasing in the percent of Dyphylline released and better retardation of drug release for tablets prepared using HPMC K100M CR, HPMC E4M CR, Compritol ATO 888, and Precirol ATO5. Similar results were obtained with ranitidine hydrochloride CR matrix tablets prepared by direct compression technique where the increase in the HPMC content led to a decreasing in the drug release (32).

All tablets prepared by direct compression except for formula $F_{24 d}$ (prepared using $21 \%$ Compritol ATO 888) recorded $\mathrm{f}_{2}$ value below 50, indicating significant differences from the reference release profile. Formula $F_{24 d}$ showed a high $\mathrm{f}_{2}$ value (82.61) and was considered promising and selected for further scaling.

\subsection{Tablets prepared by wet granulation:}

\subsubsection{Selection of the optimum conditions for wet granulation:}

\section{Table 6}

From Table 6, it is evident that the increase in the water volume from 250 to 300 and $375 \mathrm{mg} / \mathrm{tablet}$ increased MDT values indicating better retardation of drug release. This may facilitate proper wetting of the polymer, such as adding a higher amount of water, may reduce the rehydration rate of the xanthan gum matrix and decrease the time for gel layer formation and increase gel layer rigidity leading to a decrease in the percent drug released. These results were following those recorded for Niacinamide CR matrix tablets (33), which showed that increasing the water percentage produced more compact particles with a fewer of large fibers. On the other hand, the dissolution profiles of HPMC CR matrix tablets were independent of the amount of water during granulation (34).

By increasing the mean particle size of the prepared granules from 780 um to $950 \mathrm{um}$, the MDT decreased, and drug retardation ability also decreased. Tablets prepared using granules of mean particle size 1350 um entirely dissolved in $10 \mathrm{~min}$, indicating non-controlled release behavior. 
These results may lead to increasing the porosity of tablets and thus a decrease in the tortuosity of the gel layer and an increase in release rate. The smaller size of the granule range leads to a closer and more intimate packing (35). These results are in agreement with those obtained with Diclofenac sodium CR matrix tablets (36), Propranolol hydrochloride (37), and Aspirin CR matrix tablets (38). Increasing the compression force resulted in more retardation of drug release (higher MDT values). The reduction in the matrix's porosity leads to slower water uptake and waterfront moving into the matrix, which in turn leads to slower drug release (39). The compression force of $10 \mathrm{Kpsi}$ produced tablets of an acceptable release profile.

Similar results were obtained with Theophylline and Chlorpheniramine maleate (40), Phenylpropanolamine hydrochloride CR tablets (41), Hydrochlorothiazide, and Diphenhydramine hydrochloride CR matrix tablets (42). The same decrease in the release of both ionizable drugs (Pseudoephedrine hydrochloride, Phenylpropanolamine hydrochloride, and Ibuprofen) and nonionizable drugs (Theophylline, Caffeine, and Dyphylline) on increasing the compression force (43). On the other hand, it was stated that compression force had not any effect on Promethazine release (44), Propranolol hydrochloride and Aminophylline (45), Naproxen (46), and Diclofenac sodium (47). Similar results were established with Ketoprofen CR matrix tablets prepared using sodium alginate as gum type CR matrix (48).

The decrease in the tablet surface area of the Dyphylline hydrophilic tablet matrix from $16 \mathrm{~mm}$ circular tablets to $20 \mathrm{~mm}$ oblong tablets resulted in a longer MDT, indicating better retardation of drug release. The decrease in the surface area of the tablet led to the decreasing in the surface exposed for dissolution and thus a decrease in the amount of Dyphylline released. Using bisected 20 $\mathrm{mm}$ oblong punches resulted in a loss of drug retardation abilities, the tablets dissolved in $30 \mathrm{~min}$. The disruption of the tablet surface by bisection led to disruption in the gel layer's tortuosity and thus increases in amounts of Dyphylline released.

\subsubsection{Evaluation of tablets prepared by wet granulation:}

\subsubsection{Hardness and Friability:}

The Friability and mean Hardness values of the prepared tablet formulae are presented in Tables 7 and 8 .

\section{Table 7}

\section{Table 8}

From Tables 7 and 8, it is evident that all formulae prepared with different polymers and both granulating agents showed closely related values ranging from $13-17 \mathrm{~kg}$ and $0.19-0.69 \%$ for Hardness and Friability, respectively, except for formulae $\mathrm{F}_{3 \mathrm{ww}} \& \mathrm{~F}_{3 \mathrm{wi}}$ (prepared using $21 \%$ xanthan gum). The very high content of xanthan gum resulted in low Hardness and high Friability. Probably 
the high content of polymer resulted in an external wet and highly viscous layer. This layer prevented the complete hydration of the inner parts of the granules formed and resulted in more friable and weak granules after drying.

\subsubsection{In-vitro release studies:}

The data of the release of the prepared tablets were illustrated in Figures 5 and 6.

\section{Figure 5}

\section{Figure 6}

As shown in the previous Figures, the granulating liquid type showed the most pronouncing effect on Dyphylline release. Tablets prepared using water showed better retardation of Dyphylline release comparing with other tablets prepared by using isopropyl alcohol. This may lower the solubility of the used polymers in isopropyl alcohol relative to better solubility in water; thus the granulation with water tends to increase the magnitude of polymer hydration than granulation with isopropyl alcohol leading to a more intact gel layer, which decreases the rate of release. However, these results are not by those obtained with Pentixifylline CR matrix tablets prepared using either water or IPA as granulating liquids and HPMC or HEC as gum type CR matrix, where both fluids gave near related profiles (49).

Better retardation of the drug release (higher MDT values) is obtained by increasing polymer content. Tablets prepared at $7 \%$ polymer content showed short MDTs. During the dissolution of tablets with higher polymer contents (14 and 21\%), the outer hydrated layer showed a progressive increase in size, followed by a loss in integrity. So, it still unchanged until the end of the dissolution process when wetting the dry inner core till the entire tablet disappeared (50). A polymer content of $21 \%$ showed maximum drug retardation for all polymers except xanthan gum, where, further increase in xanthan gum content to $21 \%$ faster drug release is obtained from the tablets due to the low Hardness and high friability values of those tablets. Similar results were obtained with diphenhydramine hydrochloride CR matrix (51), where higher polymer content resulted in greater chain entanglement and lower diffusion coefficients for the drug. So, a slower drug release occurred. Diphenhydramine hydrochloride and Hydrochlorothiazide CR matrix tablets (52), Metoprolol tartrate (53), Indomethacin CR tablets (54), and Salicylic acid (55) showed similar results for the impact of the polymer level of drug release.

The polymer's type effect on the release retarding ability of the tablets was studied. For tablets prepared using water as a granulating liquid, xanthan gum showed the highest retarding effect 
(highest MDT values), followed by HPMC K100 CR, HEC, HPC, and HPMC E 4 CR. Sodium alginate and alginic acid recorded small MDT values indicating the low retarding effect. Upon using isopropyl alcohol as the granulating liquid, small MDT values were recorded for all polymers except for HPMC $\mathrm{K}_{100} \mathrm{CR}$ and HPC, which showed moderate release retardation.

HPMC $\mathrm{K}_{100} \mathrm{CR}$ showed higher MDT values comparing with HPMC E4 CR. The former HPMC grade has a higher ratio of hydroxypropyl to methoxyl substitution. This substitution group is essential for polymer hydration. Hydration of the polymer is required to obtain the gel barrier that should be strong to control both the drug, and water diffusion (56).

Tablet formulae prepared using 14\% xanthan gum, 21\% HPMC $\mathrm{K}_{100} \mathrm{M} \mathrm{CR}, 21 \%$ HPMC E4M CR, $21 \% \mathrm{HPC}$, and $21 \% \mathrm{HEC}\left(\mathrm{F}_{2 \mathrm{Ww}}, \mathrm{F}_{12 \mathrm{Ww}}, \mathrm{F}_{15 \mathrm{Ww}}, \mathrm{F}_{18 \mathrm{Ww}}\right.$, and $\mathrm{F}_{21 \mathrm{Ww}}$, respectively) recorded high similarity factor values $(>65)$ indicating good similarity to the reference release profile, and thus they were selected to be further studied and scaled up.

\subsubsection{Effect of combined polymers:}

Table 9 shows that combining polymers did not affect the Friability, Hardness, and content uniformity values of the produced tablets.

\section{Table 9}

The data of the release of the prepared tablets were illustrated in Figure 7

\section{Figure 7}

On the other hand, Fig. 7 shows that drug's release was significantly faster from all tablets obtained by using combined polymers about the corresponding formulae containing each of the polymers alone. This may attribute a less rigid gel layer formation with a consequent decrease in retardation capacity. Different results were reported for Tramadol hydrochloride CR tablets (57), and Diclofenac sodium CR tablets (58), were a combination of xanthan gum and HPMC led to a more significant retarding effect.

\subsubsection{Effect of addition of extra binder:}

For further optimization, the five selected formulae were prepared by adding 1\% PVP as a binder. Table 10 shows no significant change was recorded for the Friability, Hardness, and content uniformity values.

\section{Table 10}


The data of the release of the prepared tablets were illustrated in Figure 8

Figure 8

It is shown from Figure 8 that the addition of a binder to HPMC $\mathrm{K}_{100} \mathrm{M}$ CR and HPMC E $4 \mathrm{M}$ CR tablets led to a decrease in the percent of Dyphylline released compared with those formulae with no PVP K-25. This was attributed to the synergistic effect of PVP K-25 in increasing the integrity of the gel layer produced, and thus, the retardation of drug release is increased. These results are following those obtained with Dyphylline controlled-release tablets (59), where the addition of PVP $\mathrm{K}-25$ led to a decrease in drug release. These two formulae ( $\mathrm{F}_{33 \mathrm{Ww}}$ and $\left.\mathrm{F}_{34 \mathrm{Ww}}\right)$ showed high similarity factor values (83.35 and 78.1) and were selected for upscaling.

On the other hand, a significant increase in percent Dyphylline released from xanthan gum, HPC, and HEC based tablets are exhibited compared with the formulae devoid of PVP K-25, which was attributed to the competition of the polymers and the binder for the water and the relatively low solubility of PVP K-25 in water leading to the reduction in the viscosity and break-up of the integrity of the gel layer that leads to decreasing the retardation of the drug. These results are following those obtained with hydroxyl propyl methylcellulose (HPMC) extended-release tablets (60). Tablet formulae $\mathrm{F}_{33 \mathrm{Ww}}, \mathrm{F}_{34 \mathrm{Ww}}$, and $\mathrm{F}_{36 \mathrm{Ww}}$, recorded high similarity factor values (>65), indicating good similarity to the reference release profile, and thus, they were selected to be further studied and scaled up.

\subsection{Tablets prepared by the hot-melt technique:}

\subsubsection{Hardness and Friability:}

Table 11 represents that the prepared formulae showed very closely and officially accepted Friability and Hardness values.

\subsubsection{Content Uniformity:}

Table 11 shows that all formulae are complying with the pharmacopeia limits.

\section{Table 11}

\subsubsection{In-vitro release studies:}

The data of the release of the prepared tablets were illustrated in Figure 9 


\section{Figure 9}

It is shown from Figure 9 that preparing tablets using hydrophobic polymer by hot melt method succeeds in retarding the Dyphylline release. This was attributed to the heat treatment which, caused the melting of the wax, redistribution, coating both the drug and diluents as well as forming a network structure that increased tortuosity of the matrix and delayed-release (61). Similarly, the phenylpropanolamine hydrochloride release was retarded by the heat treatment with Compritol ATO 888 (62).

Increasing the hydrophobic polymer content led to a decreasing in the percent Dyphylline released and better retardation of drug release. The lipophilic controlled release matrix makes the wetting of the factual matrix difficult and subsequently allows a slower release rate (63). Theophylline controlled release matrix tablets showed a closely related behavior where the drug release was delayed when lipophilic controlled release matrix content increased.

Formula $\mathrm{F}_{24 \mathrm{H}}$ (prepared using $21 \%$ Compritol ATO 888) had an $f_{2}$ value of 81.52 and was selected for further scaling.

\subsection{Kinetic analysis of the release profile of the selected tablet formulae:}

The most suitable kinetic model for the Dyphylline in-vitro release formulae can be determined from the highest values of the correlation coefficients obtained (Table 12).

\section{Table 12}

Table (12) shows that all Dyphylline formulae obey Higuchi's diffusion model, explaining the diffusion-controlled release mechanism.

The difference in mean of First-order, Zero-order, Higuchi-kinetics, and Korsmeyer-Peppas between the different formulae " $\mathrm{K}$ " was indicating significant $(\mathrm{p}<0.05)$.

\section{6- Conclusion:}

Formulation of Dyphylline hydrophilic matrix tablets is better achieved with a wet granulation technique using water as granulating liquid. The increase in the polymer content led to increasing in $\mathrm{t}_{1 / 2}$ value and a decrease in the Dyphylline's extent released due to the improved retardation of drug release. The rate of the Dyphylline release from hydrophilic matrix tablets prepared by the wet granulation method and using either: xanthan gum, sodium alginate, alginic acid, and hydroxyethylcellulose as the hydrophilic polymer was lower upon using water as the granulation liquid compared to results obtained upon using isopropyl alcohol. This was attributed to the 
minimal solubility of these polymers in isopropyl alcohol compared to good solubility in water, which led to a decrease in the polymer hydration and the production of a less intact gel layer manifested as a decrease of drug retardation. The synergistic effect of the PVP-K-25 combined with other binders leads to retention of the release of the drug from hydrophilic matrix tablets. Diffusion is the mechanism of Dyphylline release from the controlled release tablets prepared by direct compression, wet granulation, and hot melt techniques. The formulations exhibited release profiles close to the reference release profile and recorded high similarity factor values (>65) indicating good similarity to the reference release profile, and thus, they were selected to be further studied and scaled up designated.

\section{7- References:}

1. John C, Morten C, The Science of Dosage Form Design, Aulton: Modified release peroral dosage forms. $2^{\text {nd }}$ ed. Churchill Livingstone. 2002; 290-300.

2. Patel H, Panchal DR, Patel U, Brahmbhatt T. Matrix-type drug delivery system: A review. J Pharm. Sci. Biosci. Res., 2011; 1(3):143-51. 10.

3. Dixit N, Maurya SD, Bhanu PS. Sustained release drug delivery system. Ind. J. Res. Pharm. Biotechnol., 2013; 1:305-10. 11.

4. Kola R, Kumar BP. A detailed description of synthetic and natural polymers which are used in the formulation of sustained release drug delivery system: A review. J. Chem. Pharm. Sci. 2013; 6:161-9.

5. Takasaki H, Yonemochi E, Messerschmid R, Ito M, Wada K, Terada K. Importance of excipient wettability on tablet characteristics prepared by moisture activated dry granulation (MADG) Int. J. Pharm. 2013;456:58-64.

6. Ratnaparkhi MP, Gupta JP. Sustained release oral drug delivery system - An overview. Int. J. Pharm. Res. Rev., 2013; 2:11-21.

7. British Pharmacopoeia.The Stationary Office, London, 2004, pp.2499, A358.

8. Martino PD, Joiris E and Martelli S, Particle interaction of lubricated or unlubricated binary mixtures according to their particle size and densification mechanism II. Farmaco., 2004, 59(9): 747- 758 .

9. Zhang Y, Law Y and Chakrabarti S Physical Properties and Compact Analysis of Commonly Used Direct Compression Binders. AAPS Pharm. Sci. Tech., 2003, 4(4): 1-11. 
10. Yasmeen R, Shoaib MH and Khalid H, Comparative Study of Different Formulations of Atenolol. Pak. J. Pharm Sci., 2005, 18(1): 49.

11. Ibrahim $\mathrm{Y}$ K, Olurinola $\mathrm{P} F$, Comparative microbial contamination levels in wet granulation and direct compression methods of tablet production. Pharm. Acta. Helv., 1991; 66(11):298-301.

12. Gohel M C, A review of Co-processed Directly compressible excipients. J. Pharm. Sci., 2005, 8(1): 76-93.

13. Jivraj M, Martini L G and Thomson C M, An overview of different excipients useful for the direct compression of tablets. Pharm. Sci. Technol., 2000, 3(2): 58- 63.

14. Ujwala Desai, Pravin Digambar Chaudhari, Dhaval Bhavsar, Rohinin Chavan, Melt granulation: An alternative to traditional granulation techniques, Indian Drugs, 2013, $50(3): 5-13$

15. Haritha Siddam, Niranjan G. Kotla, Balaji Maddiboyina, Sima Singh, Omprakash Sunnapu, Anil Kumar, and Dinesh Sharma, Formulation and evaluation of atenolol floating bioadhesive system using optimized polymer blends, Int. J. Pharm. Investig., 2016, 6(2): 116-122.

16. Iturriaga $\mathrm{H}$, Coello J, Maspoch $\mathrm{S}$, Porcel M, Kinetic-spectrophotometric determination of theophylline, dyphylline, and proxyphylline by use of partial least-squares regression Anal Bioanal Chem, 2002, 374(1):33-8.

17. Marcelo Blanco, Ismael Valverde Application of micellar electrokinetic chromatography to the quality control of a pharmaceutical preparation containing three bronchodilators Electrophoresis. 2002, 23(4):578-83.

18. Wei-Shan Huang, Shun-Jin Lin, Hsin Lung Wu, Su-Hwei Chen Simultaneous determination of theophylline and dyphylline by micellar electrokinetic chromatography and application in drug formulations J. Chromatogr B Analyt Technol Biomed Life Sci., 2003, 795(2):329-35.

19. Dyer J.R., Absorption of common functional groups, Application of absorption spectroscopy of organic compounds. $7^{\text {th }}$ New Delhi, Prentice Hall of India, Pvt. Ltd, 1989; 32-37. 
20. Pignatello, R., Ferro, M., De Guidi, G., Salemi, G., Vandelli, M.A., Guccione, S., Preparation, characterization and photosensitivity studies of solid dispersions of diflunisal and Eudragit RS 100 and RL 100. Int. J. Pharm, 2001; 218: 27-42.

21. Luner, P.E., Kirsch, L.E., Majuru, S., Oh, E., Joshi, A.B., Wurster, D. E, Preparation studies on the S- isomer of oxybutynin hydrochloride, an Improved Chemical Entity (ICE ). Drug Dev. Ind. Pharm, 2001; 27: 321-29.

22. Inderbir G. A., Karann M., Inderbir S., Sandeep A., Vikas R., "Formulation and Evaluation of Controlled Release Matrix Mucoadhesive Tablets of Domperidone Using Saliva Plebeian Gum." J. Adv. Pharm. Tech. and Res. 2 (3), 2012, 163- 169.

23. Goswami Dhrnba Sanker, "Formulation and Evaluation of Mucoadhesive Tablets of Famotidine." J. Pharm. \&Biomed. Sci., 2011, 12 (13), 1-3.

24. Leon Lachmann, Lieberman H. A., Kanig J. L., The Theory and Practice of Industrial Pharmacy." CBS Publishers and Distributer, 2009, 297- 301.

25. Shoaib, M Harris, Tazeen, Jaweria, Merchant, Hamid A. and Yousuf, Rabia Ismail Evaluation of drug release kinetics from ibuprofen matrix tablets using HPMC. J. Pharm. Sci., 2006, 19 (2): 119-124.

26. Higuchi T. Mechanism of sustained-action medication. Theoretical analysis of rate of release of solid drugs dispersed in solid matrices J. Pharm. Sci., 1963, 52(12): 1145-1149.

27. Esmat Zien El-Deen, Mamdouh Ghorab, Shadeed Gad and Heba Yassin, In-vitro evaluation and kinetic estimation of a proposed drug delivery system containing ketorolac, Eur. J. Pharm.\& Med. Res., 2016, 3(6): 137-148,

28. Korsmeyer R.W., Gurny R., Doelker E., Buri P., Peppas N.A. Mechanisms of solute release from porous hydrophilic polymers. Int. J. Pharm. 1983; 15:25-35.

29. Peppas N.A. Analysis of Fickian and non-Fickian drug release from polymers. Pharm. Acta Helv. 1985; 60:110-111.

30. Dorota Wójcik-Pastuszka ，Justyna Krzak , Bartosz Macikowski ，Ryszard Berkowski, Bogdan Osi 'nski and Witold Musiał, Evaluation of the Release Kinetics of a Pharmacologically Active Substance from Model Intra-Articular Implants Replacing the Cruciate Ligaments of the Knee, Materials 2019 , 12(8):1202.

31. Marc S. Gordon, Process Considerations in Reducing Tablet Friability and Their Effect on in vitro Dissolution, Drug Deve. \&Ind. Pharm., 1994, 20 (1), 11-29. 
32. T. Raja Sekharan, S. Palanichamy, S. Tamilvanan, S. Shanmuganathan, A. Thanga Thirupathi Formulation and Evaluation of Hydroxypropyl Methylcellulose-based Controlled Release Matrix Tablets for Theophylline, Indian J Pharm Sci. 2011, 73(4): 451456.

33. Rezowanur Rahman, Sheikh Tasnim Jahan, Sams Mohammad Anowar Sadat and Reza-ul Jalil, Preparation and evaluation of mucoadhesive hydrophilic hydroxy propyl methyl cellulose based extended release matrix tablets of Niacin (Nicotinic acid), Am. J. Sci. Ind. Res., 2010, 1(3): 558-564.

34. Andreopoulos AG and Tarantili PA. Xanthan gum as a carrier for controlled release of drugs. J. Biomater. Appl., 2001, 16 (1),34-46

35. Billa N. and Yuen KH. Formulation variables affecting drug release from xanthan gum matrices at laboratory scale and pilot scale. AAPS Pharm. Sci, Tch., 2000, 1(4):E30

36. Upendra Nagaich, Charu Bharti, Ashok Kumar Pal, Neha Gulatl, diclofenac Sodium Loaded Sustained Release Matrix Tablet Possessing Natural and Synthetic Polymers: Formulation and in vitro Characterization, Ind. J. Pharm.Edu. \& Res., 2014, 48: 49-55.

37. Sevgi Takka, Sangita Rajbhandari, Adel Sakr, Effect of anionic polymers on the release of propranolol hydrochloride from matrix tablets, Eur. J. Pharm. \& Biopharm., 2001, 52 (1): 75-82.

38. Paul Wan SiaHeng, Lai WahChan, Michael GEasterbrook, XiaomanLi, Investigation of the influence of mean HPMC particle size and number of polymer particles on the release of aspirin from swellable hydrophilic matrix tablets, J. Cont. Rel. 2001, 76, (1-2): 39-49.

39. Vendruscolo CW, Andreazza IF, Ganter JLMS , Ferrero C and Bresolin TMB. Xanthan and galactomannan (from M. Scabrella) matrix tablets for oral controlled delivery of theophylline. Int. J. Pharm., 2005, 296 (1-2):1-11

40. Christopher R. Younga Caroline Dietzscha Matteo Cereab Thomas Farrellc Kurt A. Fegelyc AliRajabi-Siahboomic James W. Mc Ginitya, Physicochemical characterization and mechanisms of release of theophylline from melt-extruded dosage forms based on a methacrylic acid copolymer, Int. J. Pharm. 2005, 301 (1-2): 112-120.

41. Ampol Mitrevej,Nuttanan Sinchaipanid,Nuttawat Natpoolwat \&Narakorn Naratikornrit, Fabrication of Multiunit Controlled-Release Phenylpropanolamine Hydrochloride Tablets, J. Drug Dev.\& Ind. Pharm. , 1998, 24, (8): 793-796.

42. Na Zhao \& Larry L. Augsburger, The influence of swelling capacity of superdisintegrants in different $\mathrm{pH}$ media on the dissolution of hydrochlorothiazide from directly compressed tablets, AAPS Pharm. Sci. Tech., 2005, 6, E120-E126 
43. Ludger Klimek, Helmut Schumacher, Tanja Schütt, Heidemarie Gräter, Tobias Mueck, and Martin C. Michel. Factors associated with efficacy of an ibuprofen/pseudoephedrine combination drug in pharmacy customers with common cold symptoms, Int. J. Clin. Pract. 2017, 71(2): e12907.

44. Rahul V. Haware, Chaudhari, S. R. Parakh, and A. Bauer-Brandl, Development of a Melting Tablet Containing Promethazine HCl Against Motion Sickness, AAPS Pharm Sci. Tech. 2008 , 9(3): 10061015.

45. Pongjanyakul T, Pongjanyakul T, Use of Propranolol-Magnesium Aluminium Silicate Intercalated Complexes as Drug Reservoirs in Polymeric Matrix Tablets, Ind. J. Pharm. Sci., 2012, 74(4):292301.

46. Amaral M H, José Manuel Sousa Lobo, Domingos Ferreira, Naproxen Availability from VariableDose and Weight Sustained-Release Tablets, 2001, Drug Dev, \& Ind. Pharm., 27(3):221-5.

47. Narong Sarisuta, Pilawan Mahahpunt, Effects of Compression Force and Type of Fillers on Release of Diclofenac Sodium from Matrix Tablets, 2008, Drug Dev, \& Ind. Pharm., 20(6):1049-1061.

48. Tejraj M Aminabhavi,Mallikarjuna N Nadagouda, Shrinivas D Josh, Guar gum as platform for the oral controlled release of therapeutics, J.1 Exp. Opin. Drug Del., 2014, 11 (5):753-766.

49. Rahman B. M., Islam M. A., Wahed M. I., Maruf Ahmed, Islam R., Barman R. K., Anisuzzaman A.M., and Proma Khondkar, In-vitro Studies of Pentoxifylline Controlled-Release from Hydrophilic Matrices, J. Sci. Res., 2009, 1 (2): 353-362.

50. Abdel Rahim, S., Carter, P. and Elkordy, A., Design and evaluation of effervescent floating tablets based on hydroxyethyl cellulose and sodium alginate using pentoxifylline as a model drug. Drug Des. Dev. Ther. 2015,9:1843-1857.

51. Lütfi Genç, Hadi Bilaç, Erdi Güler, Studies on controlled release dimenhydrinate from matrix tablet formulations, Pharm. Acta Helvetiae, 2000, 74(1):43-9

52. Margret Chandira, A. Pasupati , H.V. Adinarayana Innamuri , M. Komala , N.K. Agarwal , Debjit Bhowmik, Formulation and Evaluation of Diphenhydramine Hcl Rapid Release Gelcaps $25 \mathrm{Mg}$, Pharm.Innov. J., 2013, 2 (3): 1-10.

53. Gautam Singhvi, Ravi Ukawala, Harish Dhoot, and Suresh Jain, Design and characterization of controlled release tablet of metoprolol, J. Pharm. Bioallied. Sci. 2012 4(1): S90-S91.

54. Crowley B, J Hamill J, Lyndon S, McKellican J F, Williams P, Miller A J, Controlled-release indomethacin and sustained-release diclofenac sodium in the treatment of rheumatoid arthritis: a comparative controlled clinical trial, Curr Med Res Opin, 1990;12(3):143-50. 
55. Shashank Soni, Bhanwar Singh Choudhary, Shadab Ahmad, Gajendra Rathi, Extended Release Granules of Acetyl Salicylic Acid: Preparation and In-vitro Characterization, Inventi Rapid: Pharm Tech 2013, 2, 1-4.

56. Sunil C. Joshi, Sol-Gel Behavior of Hydroxypropyl Methylcellulose (HPMC) in Ionic Media Including Drug Release, Materials 2011, 4, 1861-1905.

57. Jaleh Varshosaz, Naser Tavakoli, and Fatemeh Kheirolahi, Use of Hydrophilic Natural Gums in Formulation of Sustained-release Matrix Tablets of Tramadol Hydrochloride, AAPS Pharm. Sci. Tech 2006; 7(1): E168-E174.

58. Santos H, Veiga F, Pina ME and Sousa JJ. Compaction, compression and drug release properties of diclofenac sodium and ibuprofen pellets comprising xanthan gum as a sustained release agent. Int. J. pharm., 2005, 295(1-2):15-27

59. Yosry El-said \&Fahima Hashem, In-vitro evaluation of sustained-release dyphylline tablets, Drug Dev. \&Ind.Pharm., 1991, 17 (2):281-293.

60. Pseidy L. Mamani, Roberto Ruiz-Caro, and María D. Veiga, Matrix Tablets: The Effect of Hydroxypropyl Methylcellulose/Anhydrous Dibasic Calcium Phosphate Ratio on the Release Rate of a Water-Soluble Drug through the Gastrointestinal Tract I. In Vitro Tests, AAPS Pharm. Sci. Tech, 2012, 13 (4):1073- 1083.

61. Zhang Y E, Tchao R, Schwartz J B, Effect of processing methods and heat treatment on the formation of wax matrix tablets for sustained drug release, Pharm. Dev. Technol. 2001; 6(2):131-44.

62. Yu-E Zhang, Joseph B Schwartz, Melt granulation and heat treatment for wax matrixcontrolled drug release, Drug Dev. Ind. Pharm., 2003, 29(2):131-8.

63. Ali Nokhodchi, Shaista Raja, Pryia Patel, and Kofi Asare-Addo, The Role of Oral Controlled Release Matrix Tablets in Drug Delivery Systems, Bioimpacts. 2012,2(4): 175187. 
Figures

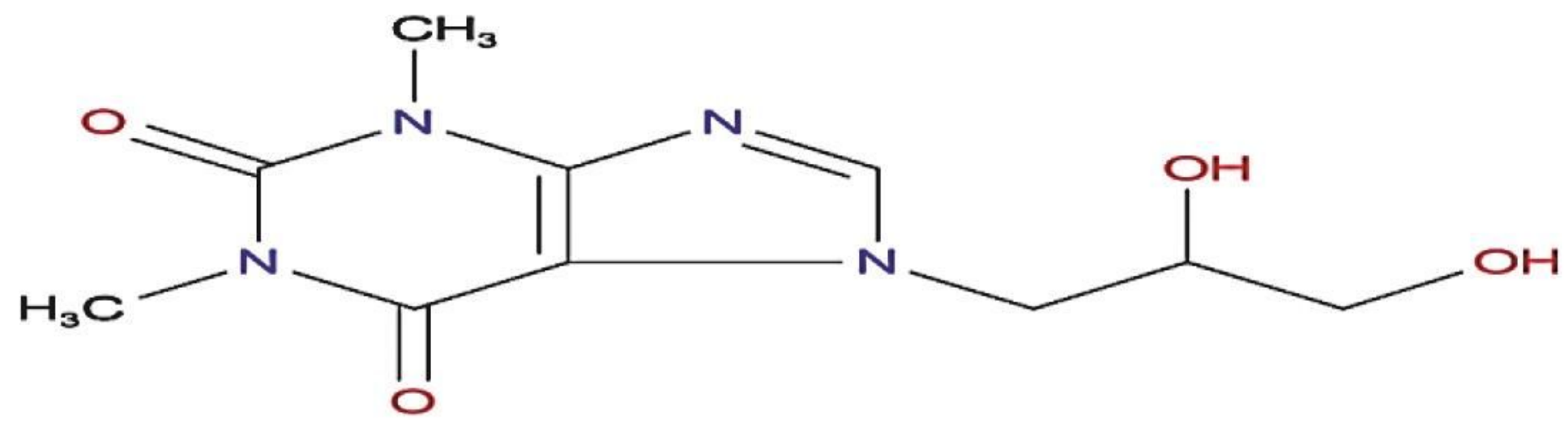

Figure 1

Chemical structure of Dyphylline 

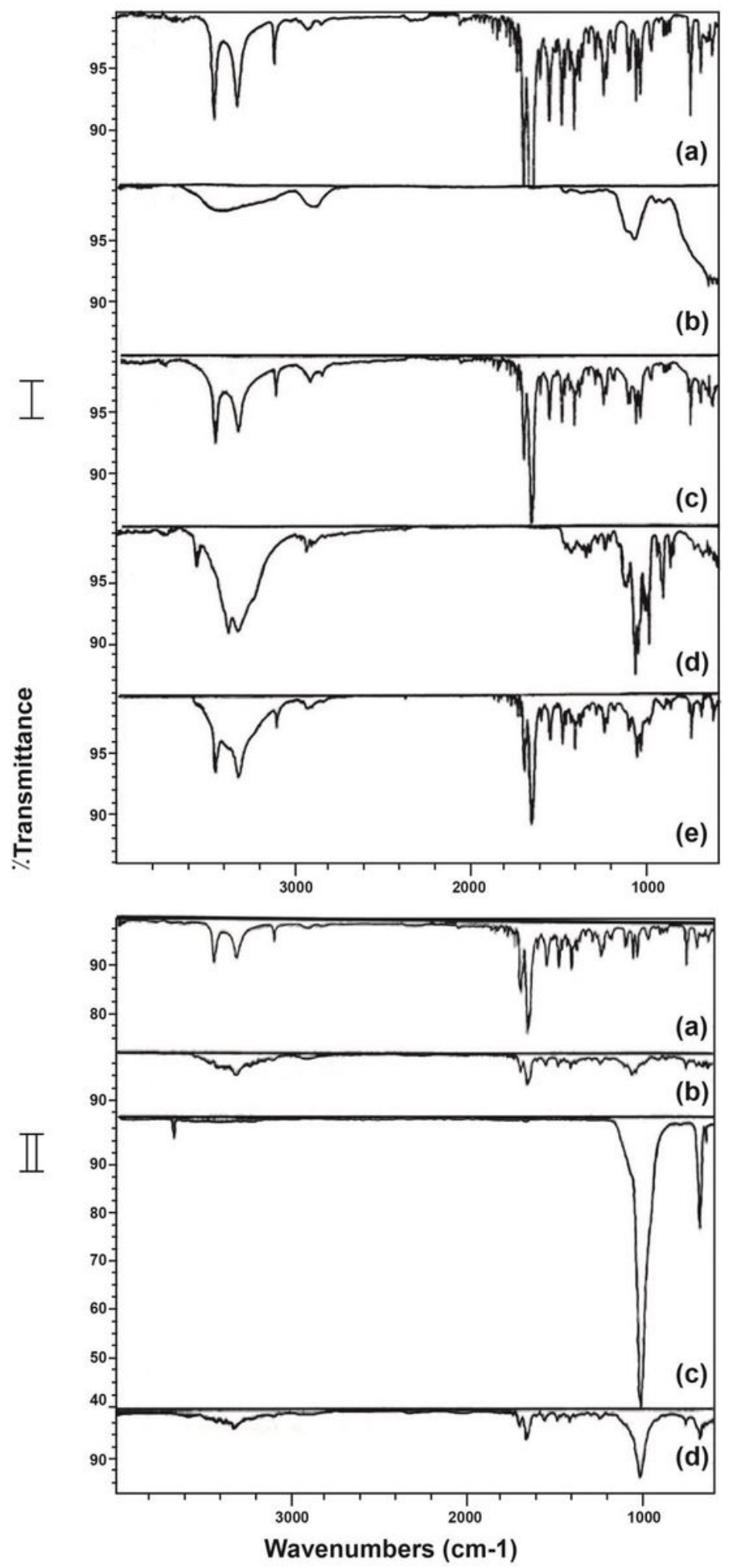

Figure 2

FT-IR spectra (I) (A) dyphylline - (B) cellulose blend (HPMC, HPC and HEC) - (C) dyphylline with cellulose blend (HPMC, HPC and HEC) - (D) Compritol and Precirol blend - (E) dyphylline with Compritol and Precirol blend. (II) (A) dyphylline - (B) Xanthan gum - (C) Alginates blend (Sodium alginate and alginic acid) and (D) Dyphylline with Xanthan gum and alginates blend 

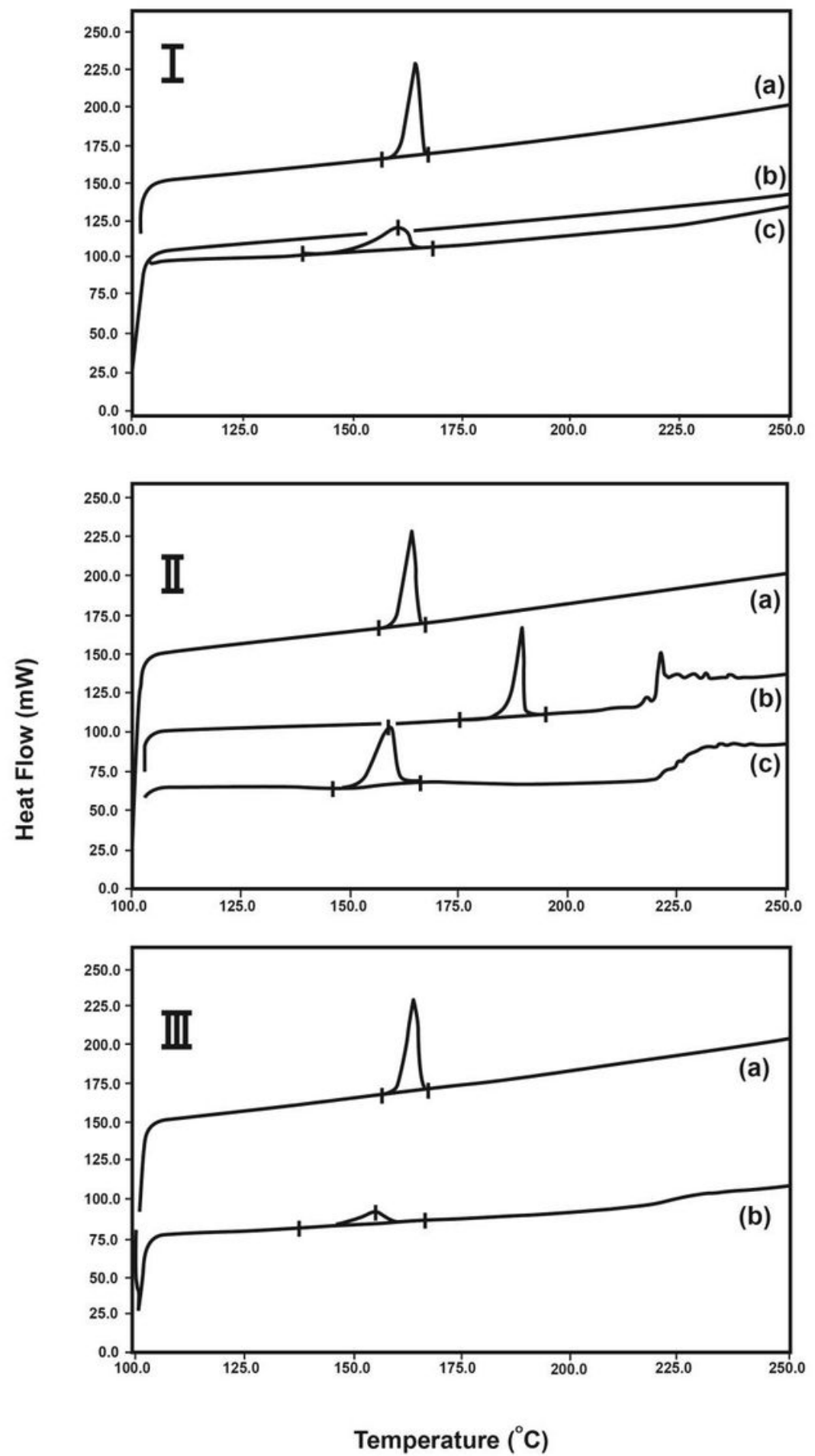

\section{Figure 3}

DSC thermograms (I) (A) dyphylline- (B) cellulose blend - (C) dyphylline + cellulose blend (II) (A) dyphylline - (B) Compritol + Precirol blend - (C) dyphylline with Compritol and Precirol blend (III) (A) dyphylline - (B) dyphylline with Xanthan gum 


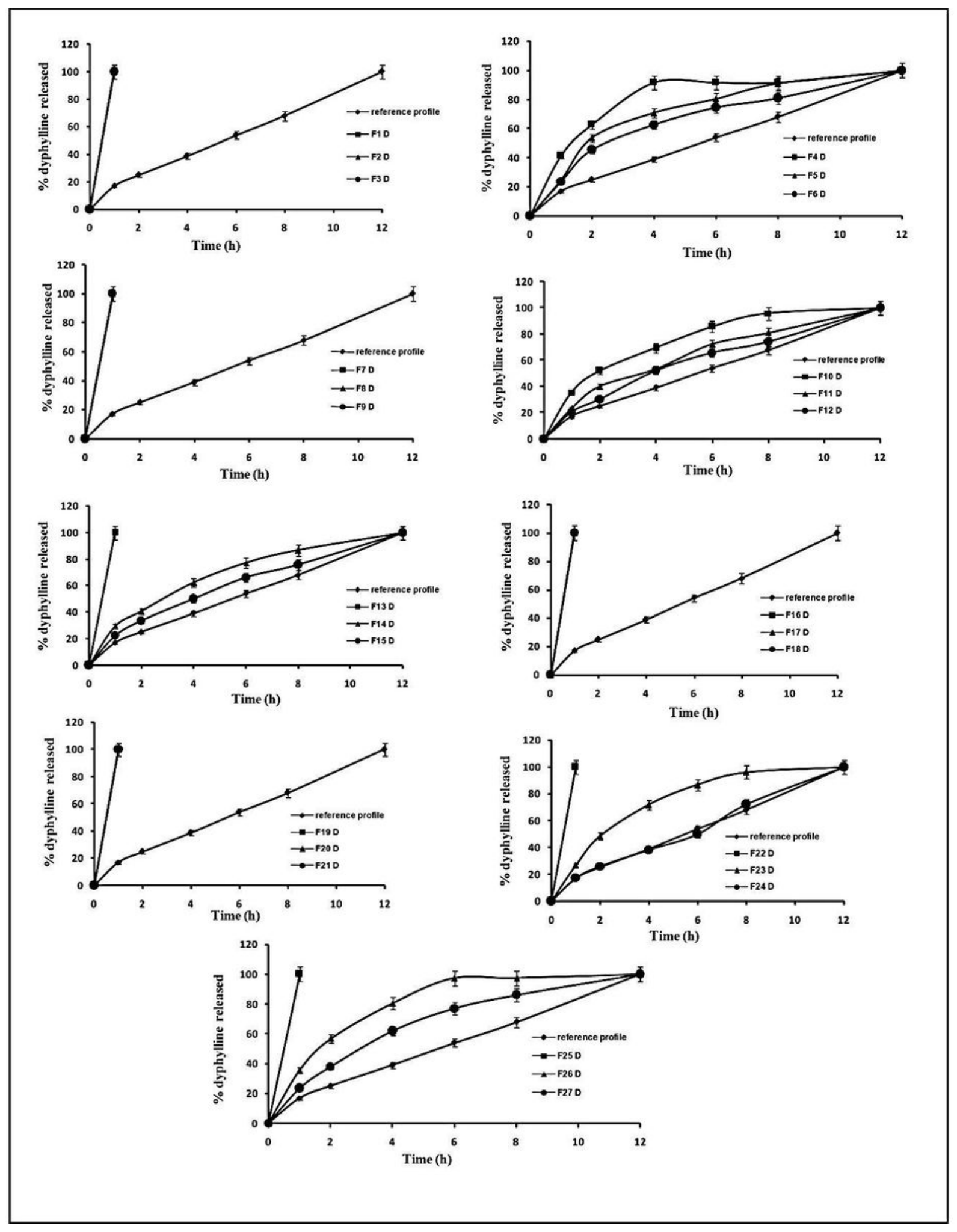

Figure 4

In vitro release profile of dyphylline from matrix tablets prepared using by direct compression technique 

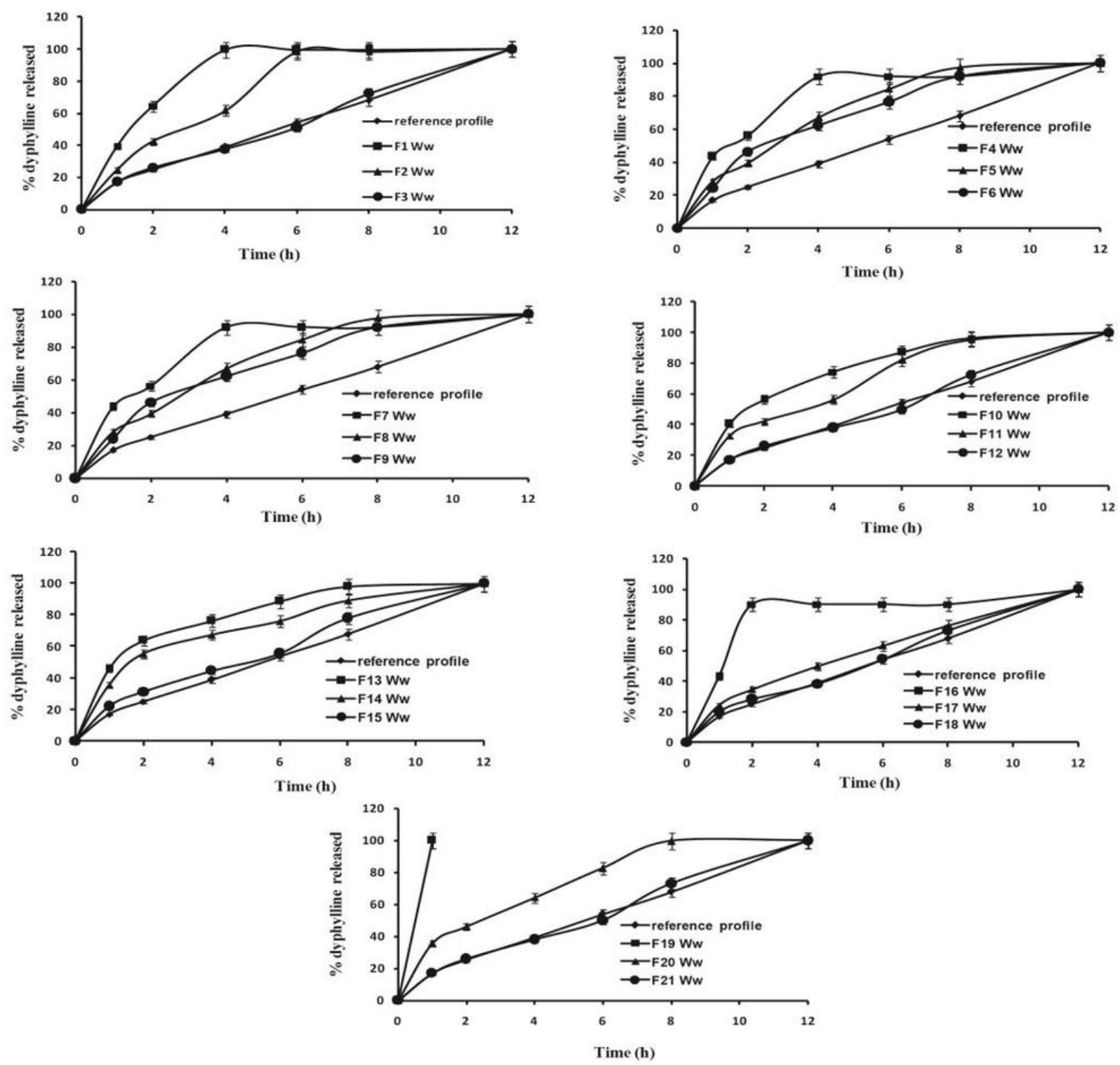

\section{Figure 5}

In vitro release profile of dyphylline from matrix tablets prepared using by wet granulation technique using water as a granulating liquid 

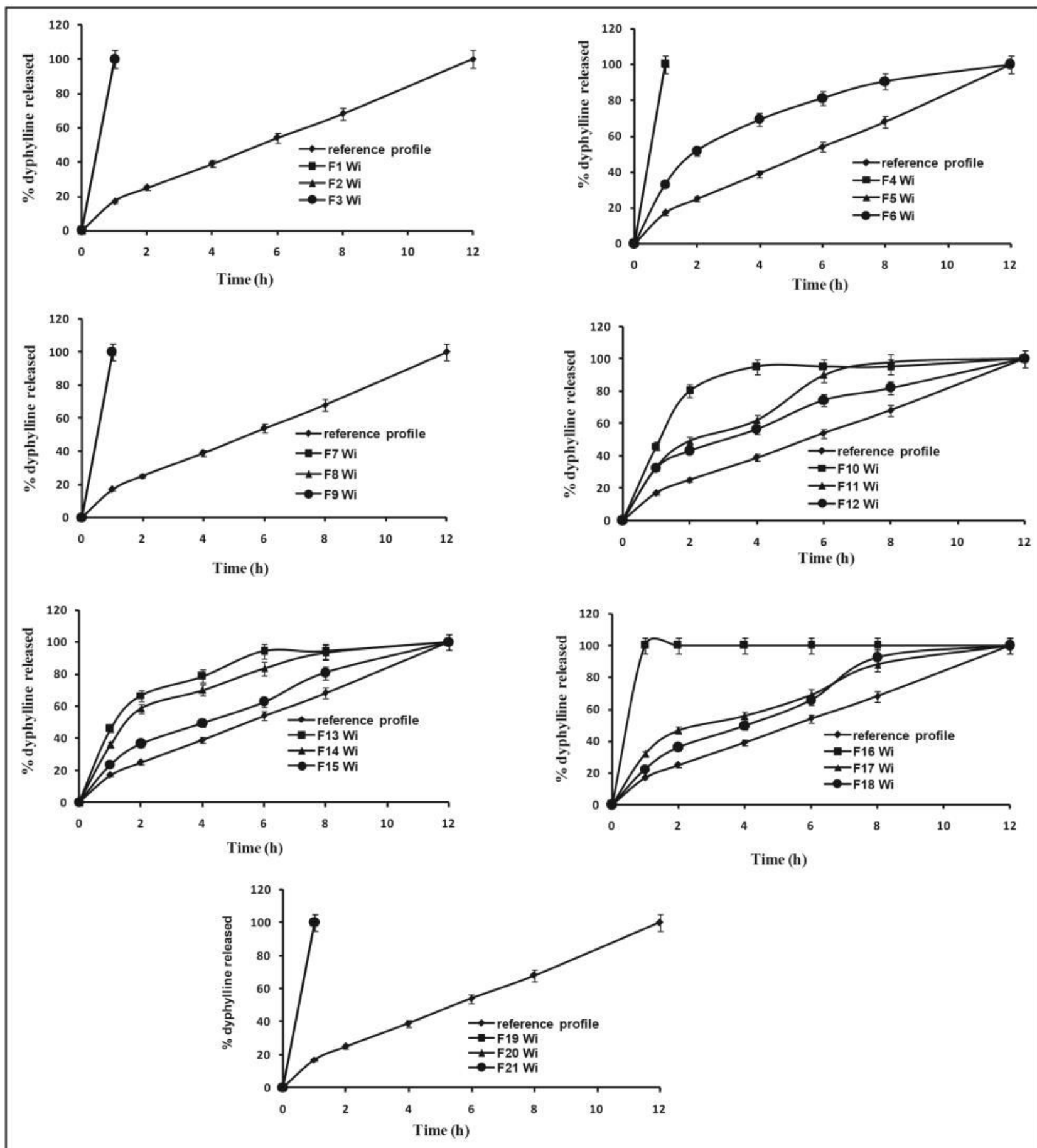

\section{Figure 6}

In vitro release profile of dyphylline from matrix tablets prepared using by wet granulation technique using isopropyl alcohol as a granulating liquid 


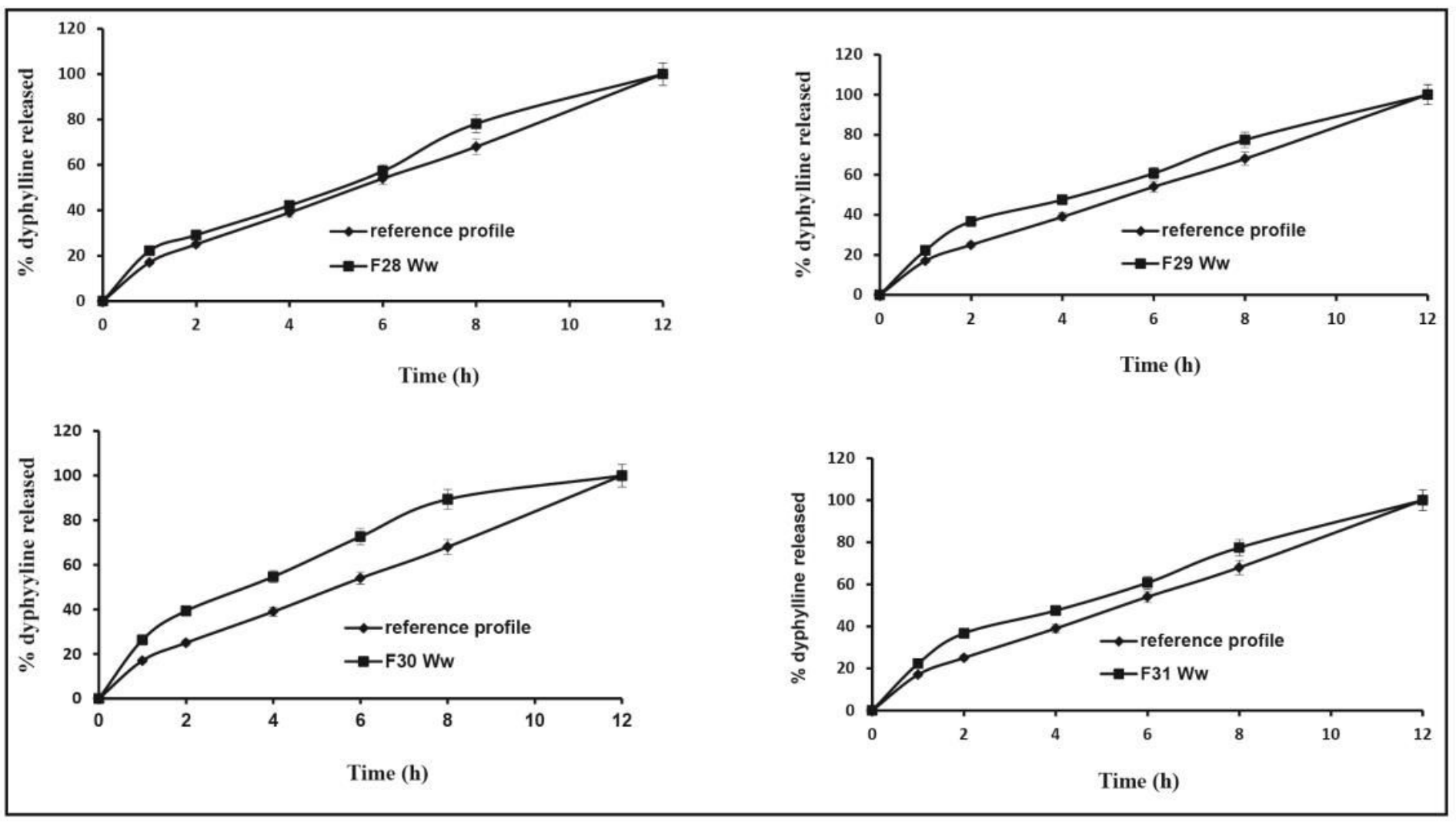

\section{Figure 7}

In vitro release profile of dyphylline from controlled release matrix tablets prepared with mixtures of hydrophilic polymers using wet granulation technique and water as a granulating liquid 


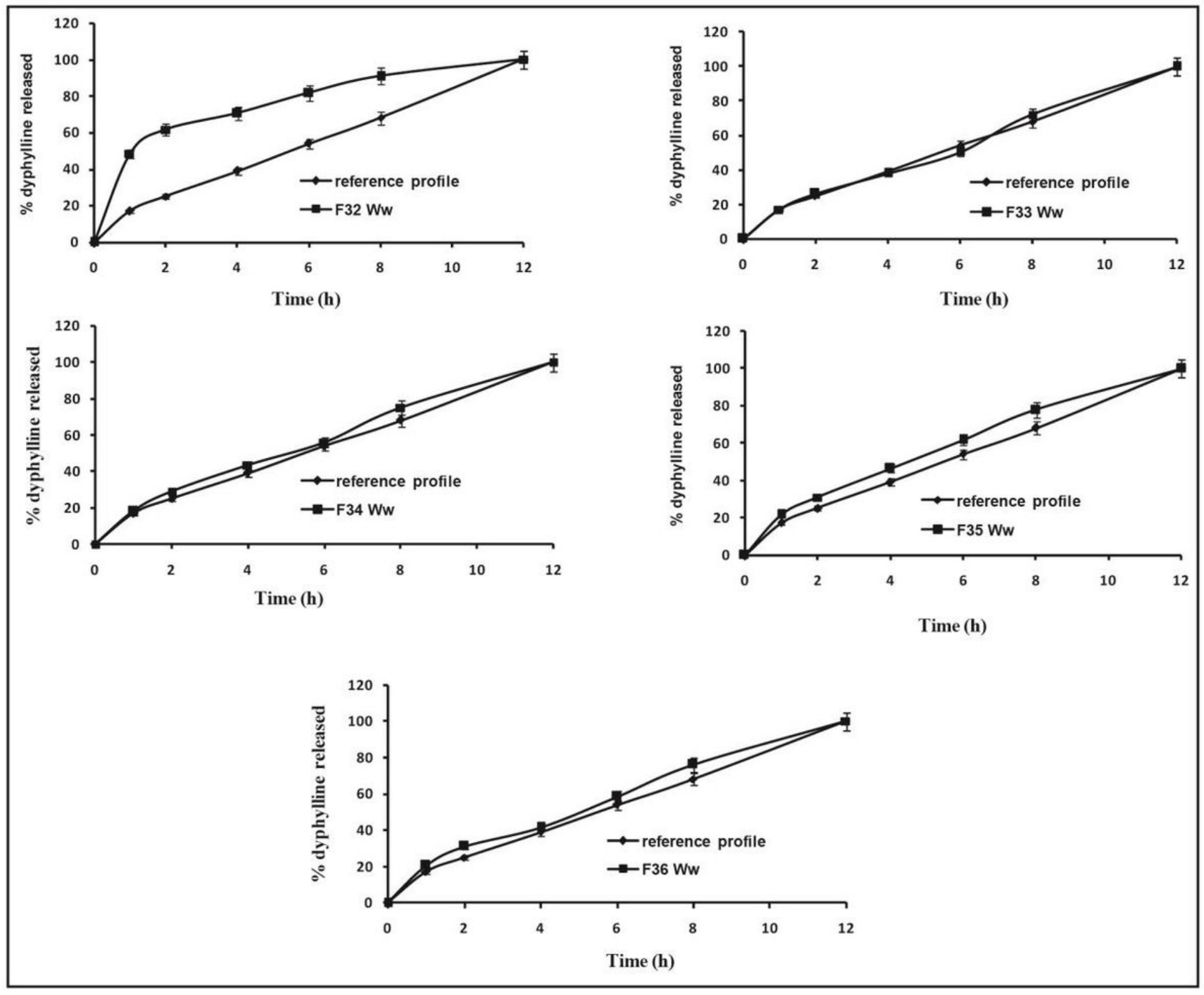

\section{Figure 8}

In vitro release profile of dyphylline from matrix tablets by using PVP K-25 as a binder prepared using by wet granulation technique using water as a granulating liquid

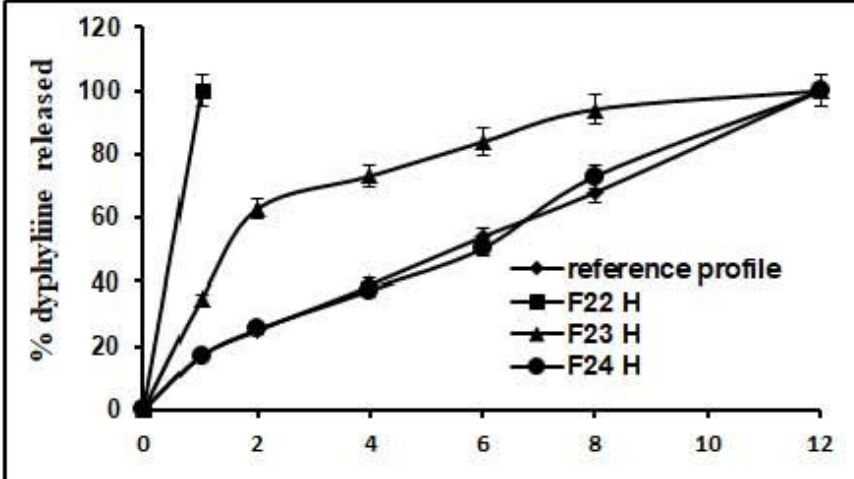

Time (h)

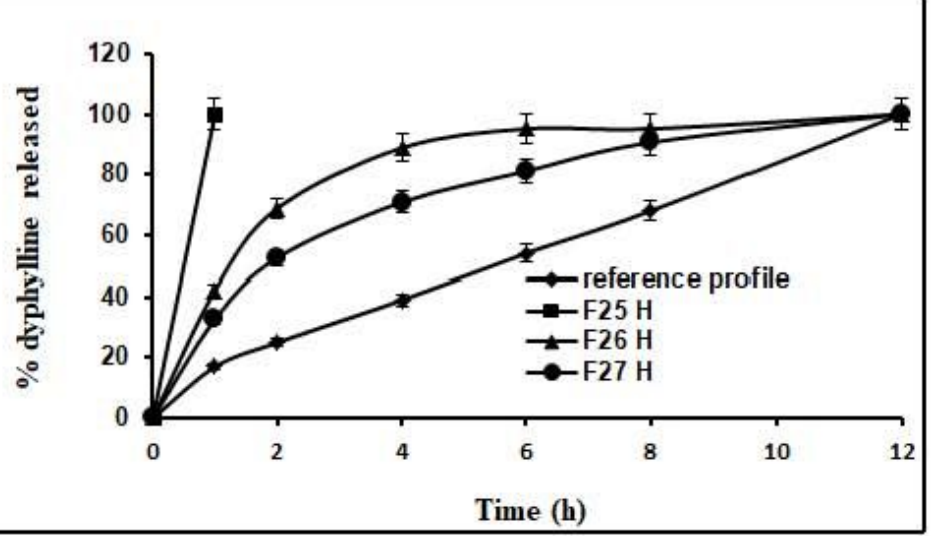


Figure 9

In vitro release profile of dyphylline from controlled release matrix using hot melt technique 